\title{
La vida y época de Marie Langer
}

\author{
por Nancy Caro Hollander
}

Traducción Claudio Cúneo

Es siempre una experiencia agridulce escribir sobre Marie Langer porque esto simultáneamente la acerca pero también me recuerda que se fue. Nos hicimos colegas y buenas amigas a principios de los años 80, cuando ambas fuimos forzadas a dejar la Argentina en vísperas del golpe militar del año 1976 que dió inicio a la Guerra Sucia de la dictadura. Cuando nos encontramos, ella en Ciudad de Méjico y yo en Los Angeles, cada una de nosotras estaba comprometida, junto a otros profesionales de salud mental, en proyectos de solidaridad que apoyaban a los sobrevivientes del régimen argentino militar, así como a refugiados de otras dictaduras militares sudamericanas y guerras civiles en Centroamérica. Mientras el psicoanálisis había sido el foco de su vida profesional, en ese momento histórico esto fue solo en parte ya que Langer se comprometió en el activismo por los derechos humanos.

Durante los cinco años anteriores a su muerte por cáncer en 1987, viajé frecuentemente a Ciudad de México a visitarla y a colaborar con un proyecto psicoanalítico único que voy a describir más adelante. Langer tenía entonces unos setenta años, cabellos canosos que enmarcaban su cara bronceada y unos sorprendentes ojos azules. Su español con fuerte acento Vienés, su juvenil encanto y una energía ilimitada desmentían su edad. Ella tenía un carisma personal que atraía a la gente y que facilitó su eficacia como coordinadora. Ella era también la analista con quien cada uno hubiera querido estar en tratamiento. En ese entonces mi formación como historiadora era el lente a través del cual pude entender una figura única y significativa de la historia del psicoanálisis, cuya vida representó la convergencia de muchos de los temas importantes del siglo XX. Quise remediar el hecho que ella era prácticamente desconocida dentro de las comunidades analíticas norteamericanas y europeas. Con esa finalidad, durante varios años registré más de 60 horas de entrevistas con ella en su casa de Ciudad de Méjico y Nicaragua, que dieron como fruto una extraordinaria información biográfica y reflexiones personales sobre su vida y su trabajo. Presento aquí en un breve relato, algunos aspectos de la vida de una de las más amadas e influyentes psicoanalistas latinoamericanas.

Marie Lisbeth Glas nació y creció en la Red Viena como la chica de familia judía de clase media que era y cuyos valores y actitudes fueron moldeados por la política cultural del exaltante partido Social Democráctico de la ciudad. La educación previa a la universitaria de Marie fue impregnada por ideas provenientes del psicoanálisis, el marxismo y el feminismo y estos tres modos de pensar serían determinantes, aún cuando de manera diversa, para el resto de su vida.

Mientras estaba terminando la carrera médica, el Austro-fascismo había alcanzado el poder, impidiéndole en cuanto judía, la obtención de una residencia.

Otras profesiones alternativas la condujeron al psicoanálisis, se inscribió y fue luego candidata en el Instituto de Freud Weiner Vereinigung Institut. Su formación incluyó tratamiento psicoanalítico con Richard Sterba, seminarios con Helen Deutsch y supervisión con Jeanne Lampl de Groot. Marie militaba simultáneamente en los movimientos de izquierda que luchaban contra el Austro-fascismo a fines de los años 30 y fue entonces que tomó la difícil decisión de dejar el Instituto para acompañar a su colega y futuro marido, Max Langer, junto a otros profesionales 
de la salud, en su viaje a España a ofrecer tratamiento médico a los soldados de la República que luchaban contra la embestida del régimen fascista de Franco.

Las extenuantes experiencias con los heridos en las batallas de la Guerra Civil Española dejaron marcas indelebles de innumerables pérdidas que incluyeron varios abortos y el nacimiento de una niña que murió después de tres días por la falta de una incubadora.

Con la derrota de la República Española y el estallido de la guerra en Europa, Max y Marie Langer se unieron a decenas de miles de refugiados que buscaban un lugar seguro donde vivir. Se establecieron primero en Uruguay y luego de varios años de pobreza, junto al primero de sus cinco hijos, se mudaron a Buenos Aires donde pudieron hacer amigos estables y lograr un éxito profesional que les permitió echar raíces en su nueva tierra adoptiva.

En 1942, Marie Langer fue la única mujer de los 5 fundadores de la Asociación Psicoanalítica Argentina (APA), que fue formalmente reconocida por la IPA varios años más tarde. La dos décadas siguientes se caracterizaron por su compromiso frenético en la construcción del Instituto Psicoanalítico más prestigioso de América Latina, cuya influencia se sintió a lo largo de todas las comunidades científicas y profesionales.

La Buenos Aires cosmopolita y europea ofreció un ambiente propicio para la difusión del psicoanálisis así como en la cultura popular que en la cultura en general: artistas, cineastas y politólogos se apropiaron de sus ideas más radicales. Como Langer, la mayoría de los psicoanalistas de la primera generación, provenían de una tradición que vinculaba el psicoanálisis con otros pensamientos radicales, incluído el marxismo, y que direccionaban los impedimentos subjetivos e institucionales a la potencialidad liberatoria humana. No obstante, durante los años formativos de APA, ellos se focalizaron en la creación de una sociedad / institución altamente profesional, que incluyó la difusión del psicoanálisis a un público amplio a través de programas de radio, artículos en diarios y la distribución de la Revista de Psicoanálisis en ámbitos profesionales y universitarios así como en librerías y kioskos. Mientras prosperaban sus prácticas privadas con la clase media y media alta, ofrecían formación psicoanalítica y soporte a los hospitales públicos y a los pacientes de clase obrera.

Langer fue una figura central de estos esfuerzos. Su dinamismo personal y sus capacidades clínicas atrayeron a numerosos leales seguidores y su voz tuvo un gran peso en las luchas internas que se desarrollaron en APA en los años siguientes. Ese carisma tan magnético que yo había descubierto ya se percibía entre sus colegas lo que generaba resentimientos por su incomparable popularidad entre los candidatos. Estos últimos soportaban largas listas de espera para poder hacer sus análisis didácticos con ella.

Era una pensadora independiente y Langer a menudo aparecía como antipática ante sus colegas, como cuando con Enrique Pichon-Riviére fundaron la Asociación Argentina de Psicología y Psicoterapia de Grupo, a la que en su momento se opusieron varios miembros de la APA sosteniendo la impractibilidad del psicoanálisis en encuadres grupales.

Tanto Langer como Pichon-Riviére compartieron la convicción sobre la naturaleza primariamente social de los seres humanos cuyas determinantes histórico, sociales y políticas en la conformación del yo, eran consideradas por ambos como analizables en grupos.

Poco después de su llegada a Buenos Aires, Langer tradujo el trabajo de Melanie Klein al español y, como hicieran por esa época muchos de sus colegas, eligió las teorías de Klein para comprender los estados mentales primitivos. Se sintió especialmente atraída por las ideas de Klein sobre el desarrollo psicosexual de la mujer que ella consideró una corrección importante a las ideas falocéntricas de Freud sobre la femineidad. Aunque ella escribió y dió conferencias 
sobre muchos temas, fue durante los años cincuenta, sesenta, que devino muy conocida por sus colegas de toda latinoamérica a partir de su trabajo acerca de varios aspectos de los desórdenes psicosomáticos en las mujeres.

Su perspectiva Kleiniana se caracterizaba por un acercamiento interdisciplinario y feminista al tema, tomando distancia de los puntos de vista conservadores sobre el rol de las mujeres que en ese período dominaban el psicoanálisis.

Maternidady sexo fue su trabajo más importante sobre este tema y por su expreso pedido personal, lo traduje más tarde al inglés. Fue publicado en 1970, junto con una publicación posterior que analiza la evolución de sus ideas, en los 80 , y que incorpora nuevos conceptos emergentes de la segunda ola feminista. Langer fue capaz de integrar su identidad como psicoanalista y como militante política que empezó en los inicios de los tumultuosos años 60 en Argentina.

Como toda la jóven generación de psicoanalistas argentinos, ella leía las radicales teorías sociales de Althusser, Adorno, Habemas y Lukács entre otros. Durante el período cada vez más represivo que llevó al golpe militar de 1976, Langer aparece como una importantísima figura militante en los movimientos de los derechos humanos de psicoanalistas y de otras profesiones de salud mental, que trataban de frenar el empuje al régimen autoritario.

En el año 1974 fue amenazada de muerte por una infame organización paramilitar de ultra derecha. Forzada a abandonar abruptamente el país, devino una refugiada política por segunda vez en su vida. Eligió exiliarse en Ciudad de Méjico donde vivían sus dos hijas con sus respectivas familias y ciudad en la que conocía una comunidad de colegas. Allí volvió a sufrir los mismos efectos traumáticos del exilio que afectaron a los pacientes que ella misma trató entre los miles de refugiados que huían de los tormentosos desórdenes politicos a lo largo y lo ancho de las Américas.

Pero junto con las pérdidas aparecieron nuevas oportunidades que le permitieron vivir este capítulo de su vida con pasión y optimismo. Fue un período reparatorio después de haber sido testigo de la destrucción de la psiquis y cuerpos de decenas de miles de personas por parte de regímenes militares de derecha. En Julio de 1979, la Revolución Sandinista en Nicaragua que sucede al derrocamiento de la dictadura de Somosa, se dispuso a reformar siglos de desigualdad social institucional y el trauma de décadas de represión política. El nuevo gobierno invitó a Marie Langer y a varios psicoanalistas argentinos que vivían en Ciudad de Méjico, a crear un dispositivo de salud mental orientado psicoanalíticamente en el interior del Primer Sistema de Salud gratuito del país. Sería un experimento único, por primera vez el diálogo Marx-Freud se iba a poner en práctica. En los siguientes 6 años, desde su cargo de Co-coordinadora del Equipo Internacional de Trabajadores de Salud Mental Méjico-Nicaragua, Marie Langer desarrolló programas de información / formación psicoanalitica, enseñando en diferentes tipos de dispositivos y supervisando a psicólogos, médicos y trabajadores sociales, distintas modalidades de psicoterapia de grupo, individual y de familia. Organizó también grupos Balint, una práctica que había iniciado en Argentina, a través de los cuales los miembros del Equipo trabajaban con los médicos para enseñarles los aspectos psicológicos de su trabajo y de la relación con pacientes, centrándose en temas como transferencia y contratransferencia. El trabajo era potencialmente peligroso porque Nicaragua se constituyó en el único modelo radical de cambio social en Latinoamérica elegido por Sandinistas: una economía mixta, una democracia multipartidaria y una política exterior no alineada que podia amenazar los intereses de Estados Unidos en la región, por lo que se convirtió en un objetivo de la agresión económica y militar de ese país. Sin embargo, esto para Langer, la oportunidad de desarrollar el psicoanálisis en un contexto social de 
ayuda al gobierno en la atención de las necesidades básicas de su población (casa, empleo, salud y educación) fué entusiasmante. Su equipo, tomando como referencia los principios básicos del psicoanálisis, los adaptó a las emprobrecidas condiciones de Nicaragua como los diez mandamientos, y Langer esperó fervorosamente poder escribir sobre esta experiencia de "psicoanálisis sin tutor". Estaba apasionada con el modelo según el cual las finalidades terapéuticas de su práctica psicoanalítica venían acompañadas y reforzadas por las oportunidades ofrecidas a sus pacientes de experimentar su canalización a través de la participación en las organizaciones sociales Sandinistas de masa creadas para combatir la histórica opresión de mujeres, trabajadores, campesinos, refugiados y minorías sexuales.

Cuando viajé a Nicaragua con Langer pude observar el trabajo de su equipo. Me llamó mucho la atención su habilidad para dialogar con sensibilidad y a su vez respeto de las personas pertenecientes a una clase social, etnia, identidad cultural muy diferentes a la suya. Me contó que ese trabajo era para ella extremadamente significativo porque le hacía sentir como si hubiera vuelto atrás a la Guerra Civil Española, sólo que esta vez la ganó la República.

Fue fácil para todos los que conocieron y admiraron a Langer idealizarla, quizás porque ella misma nunca cayó víctima de idealizaciones, ni propias ni de otros. Yo entendí que esta capacidad de Marie tenía relación, en parte, a su perspectiva kleiniana en torno a la destrucción del individuo y a su convicción de que una buena disposición para aceptar la culpa depresiva provocada por la propia agresividad, daba lugar a capacidades reparatorias. Su actitud tolerante era contagiosa entre sus amigos y colegas y su presencia funcionaba como contenedora de interacciones potencialmente antagónicas. Su capacidad para aceptar la naturaleza conflictiva de lo intra-psíquico y de la experiencia intersubjetiva fue siempre evidente, sobre todo frente a las direcciones contradictorias de los movmientos politicos. Por ejemplo, ella me contó que apoyaba la Revolución Nicaraguense como Marxista, aún con sus contradicciones, y que estaba enfurecida por la agresión de EEUU. Y como psicoanalista, ella entendía que aún aquellos individuos más comprometidos en revertir las relaciones de explotación social en nombre de la justicia social, podían fallar en sus cometidos por razones psicológicas. "Si me preguntaran para qué sirve el psicoanálisis más allá de transformar los síntomas....” explicaba, “...digo siempre que sirve para que uno no se mienta más a sí mismo”. Así que ella no idealizaba la Revolución Nicaraguense sino que más bien la abrazaba con sus paradojas y limitaciones.

Este extraordinario capítulo de la vida de Marie Langer se interrumpe abruptamente cuando se le diagnosticó un cáncer inoperable. Volvió a la Argentina a vivir sus últimos meses de vida. Murió el 22 de Diciembre de 1987, rodeada por su familia.

Su vida y su obra fueron públicamente reconocidas a través de conmemoraciones en Argentina, Méjico y Nicaragua. Quizás una de las más significativas fue la invitación que recibió poco antes de morir, para participar en una conferencia sobre "La pérdida de la razón y su regreso", organizada por el gobierno austríaco en honor a destacadas figuras de las ciencias y las artes que fueron forzadas a abandonar el país después del Anschluss (anexión) en 1938. Langer estaba muy enferma para viajar y la carta que escribió a los organizadores expresando su pesar por no poder asistir, fue leída públicamente a los participantes a la conferencia quienes respondieron con una ovación, reconociendo su contribuciones al psicoanálisis y a los derechos humanos.

Estas breves notas biográficas no hacen justicia a la vida y la obra de Marie Langer, quien fuera una figura única en la historia del psicoanálisis. Afortunadamente ella emer-ge aquí, o por lo menos se esboza, como una mujer que se esforzó por desarrollar un psicoanálisis cuya práctica teórica y clínica estuviera comprometida con lo social, así como contra las amenazas psi- 
cológicas al bienestar humano. Como Langer en momentos significativos de su vida, nosotros estamos enfrentando esos mismos desafíos paralelos: ocuparnos de nuestros pacientes, de sus/ nuestras ansiedades crecientes provocadas por un mundo social amenazante, y la preocupación por cómo desarrollar un activismo psicoanalítico que contribuya a afrontar mejor los peligros actuales.

Para más información sobre la vida y la época de Marie Langer:

- HOLLANDER, N. C. (2010). Uprooted Minds: Surviving the Politics of Terror in the Americas. New York: Routledge.

- HOLLANDER, N.C. (1985). Psychoanalysis in the Service of the People. In PsychCritique, V. I, No. 1, pp. 67-79.

- HOOKS, M. (1985). Interview with Marie Langer and Ignacio Maldonado. In PsychCritique, V. 1, No. 1, pp. 79-91.

- LANGER, M. (1989). From Vienna tio Managua (M. Hooks, translator). London: Free Association Books.

- LANGER, M. (1992). Motherhood and Sexuality (N.C. Hollander, translator and author of Introduction and Afterword). London: Guilford Press. 